\title{
MEASUREMENTS OF STATIC AND DYNAMIC DISPLACEMENT FROM VISUAL MONITORING OF THE HUMBER BRIDGE
}

G A Stephen BSc, $\mathrm{PhD}^{1}$,

J M W Brownjohn BSc, PhD, CEng, MIMechE ${ }^{2}$,

C A Taylor BSc, PhD, CEng, $\mathrm{MICE}^{3}$

${ }^{1}$ Research Student, University of Bristol,

now Research Officer

School of Electronic Engineering Science

University College of North Wales

Dean Street

Bangor

Gwynedd LL57 1UT

UK

${ }^{2}$ Research Fellow

${ }^{3}$ Reader

Department of Civil Engineering

University of Bristol

Queen's Building

University Walk

Bristol BS8 1TR

UK

\begin{abstract}
A visual tracking system has been employed in the measurement of deck displacements at the centre of the $1410 \mathrm{~m}$ span of the Humber Bridge. The transputer-based system was developed for applications such as the monitoring or testing of large physical structures, where the actual displacements may not easily be otherwise determined. The system employs parallel processing techniques to track predictively the motion of multiple, independent objects at video frame rate. Results obtained using the system in a monitoring programme of the bridge are presented and discussed.
\end{abstract}




\section{INTRODUCTION}

This paper describes a visual technique used to measure the motion of the Humber Bridge (Figures 1 and 2) at its mid-span position under ambient excitation. A real-time video tracking system was developed for this purpose, and was employed in an extensive monitoring programme. This covered a wide range of loading conditions and provided a comprehensive set of bridge-deck displacement data ${ }^{1}$.

The visual monitoring work was part of a program of experimental studies on the bridge undertaken by the Bristol University Earthquake Engineering Research Centre (EERC) to complement and augment experimental studies carried out by Politecnico di Milano. The aim of all this experimental work ${ }^{2}$ was to provide a large body of data to validate and calibrate mathematical modelling of the aerodynamic response of very long suspension bridges $^{3}$. The mathematical modelling devised by Politecnico di Milano is intended for use in future bridge designs, in particular the proposed combined road and rail crossing of the Straits of Messina linking Sicily with Calabria on the Italian mainland ${ }^{4}$, which would have a main span approximately $3300 \mathrm{~m}$ in length.

\section{THE NEED FOR FULL-SCALE DISPLACEMENT DATA}

For very long span bridges the aerodynamic and aeroelastic behaviour is a particular problem. In addition to the static loads due to mean wind speeds and buffeting forces due to fluctuating wind pressure there are self-excited forces due to the rotational and translational motion of the bridge in the air stream.

The vertical forces per unit length of deck in a horizontal wind V can be approximated as

$$
m \ddot{y}+c \dot{y}+k y=1 / 2 \rho B V^{2} C_{L}+1 / 2 \rho B V^{2} f_{s e c t}(V, \varphi, \dot{\varphi}, \dot{y}) \ldots \ldots \ldots \ldots \text { 1) }
$$

where $\mathrm{m}, \mathrm{c}$ and $\mathrm{k}$ are mass, damping and stiffness per unit length, $\mathrm{y}$ and $\phi$ are defined in Fig. 3, $\rho$ is air density, $B$ is section width (Fig. 2), $C_{L}$ is lift coefficient and $f_{\text {sect }}$ is a function of the deck section for the given variables.

The first term on the right hand side of 1) represents the external forcing function, the second term the self-excited force. Writing $\mathrm{V}$ as the sum of a mean $\bar{V}$ and a fluctuating component $V(t)$, the external force is $1 / 2 \rho B \bar{V}^{2} C_{L}+\rho B \bar{V} V(t) C_{L}$ to first order, representing a force which is static over the period of measuring $\nabla$ plus a buffeting force which depends on wind turbulence represented by $\mathrm{V}(\mathrm{t})$.

At high wind speeds a form of stability termed torsional divergence may arise due to static forces but the more significant problem is flutter due to the self excited forces. In general a high value for critical wind speed for flutter requires the right sort of deck aerodynamic properties $f_{\text {sect }}$ and adequate separation of fundamental torsional and vertical natural frequencies in still air. For the Stretto di Messina crossing the aerodynamic properties of 


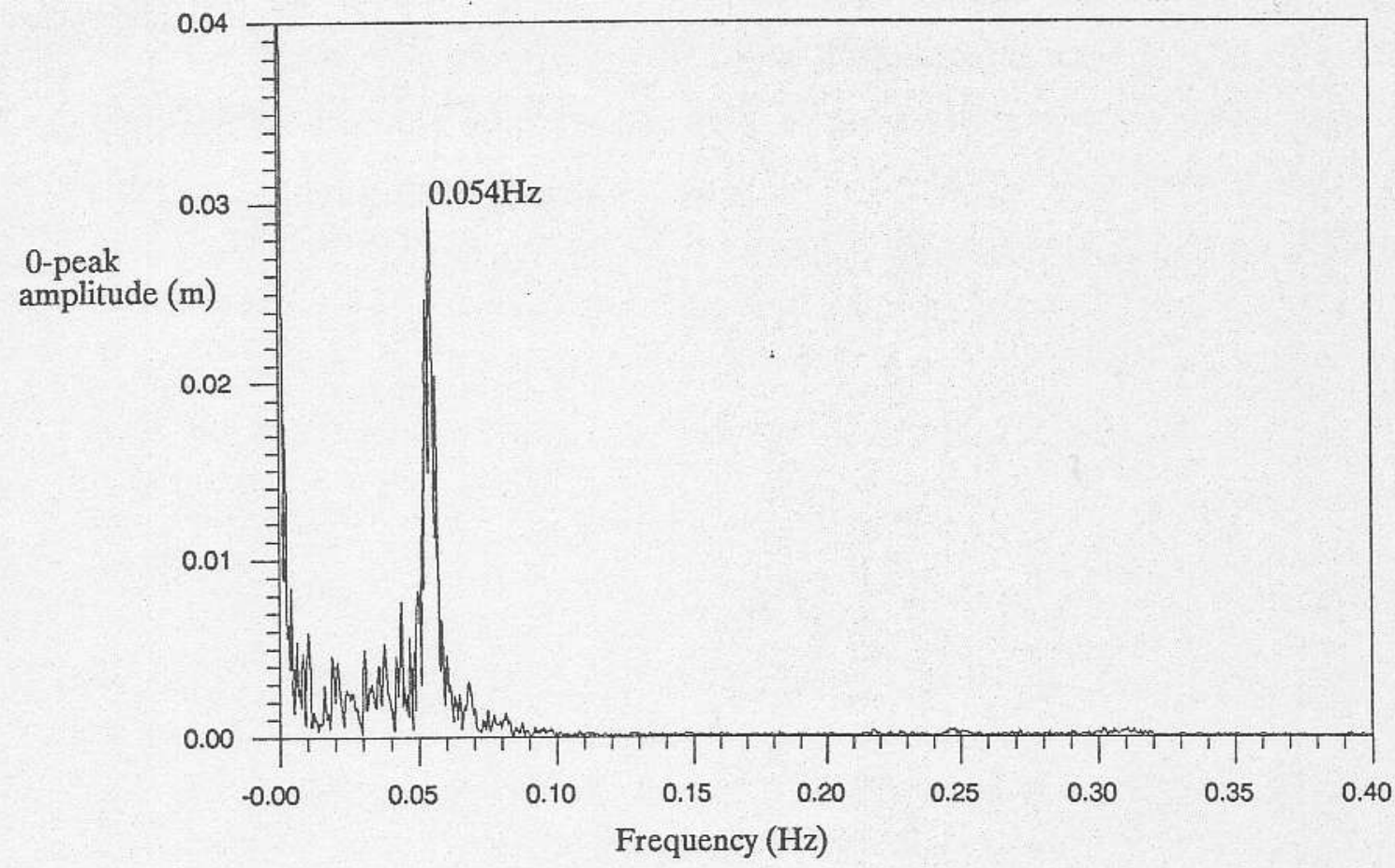

Fig. 13 Auto power spectrum of lateral deck displacement at midspan

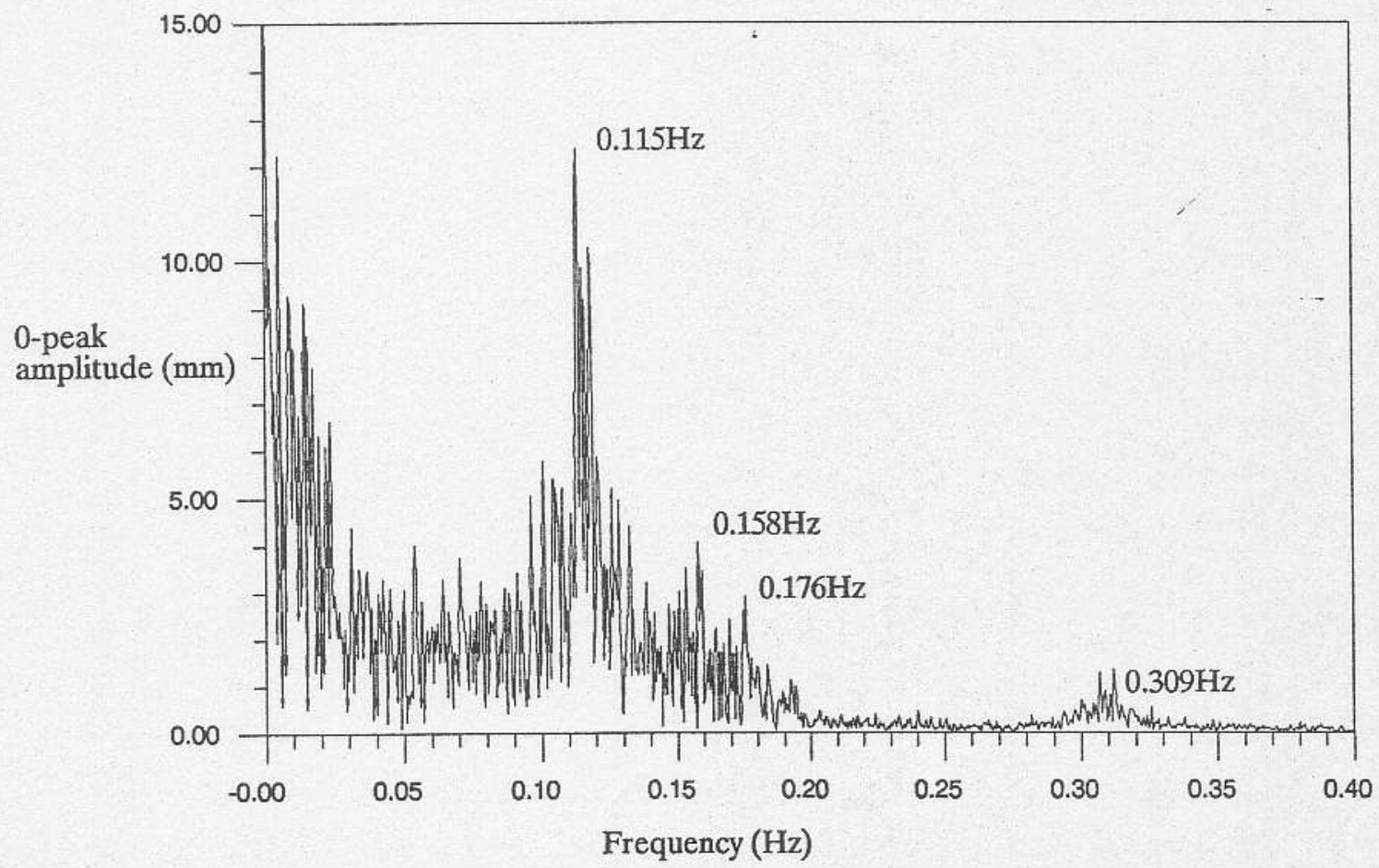

Fig. 14 Auto power spectrum of vertical deck displacement at midspan 
different sections, determined in sectional model wind tunnel studies, are used as parameters for deriving the self-excited forces in finite element analyses using synthetically generated turbulent wind data ${ }^{3}$. The accuracy of the predicted response can only be confirmed by example experimental studies.

The Humber Bridge was chosen as the subject for such experimental studies as its main span of $1410 \mathrm{~m}$ was at the time the longest of any in the world. The outcome has been validation of the modelling, a check on the aerodynamic properties determined from the wind tunnel studies and better understanding of the spatial and temporal structure of wind.

The instantaneous external wind forces depend on drag, lift and moment coefficients $C_{D}, C_{L}$ and $C_{M}$ and their derivatives with respect to angle of attack, $\alpha$. Some measure of these values can be obtained directly via measurement of static displacements so that static deflections during high winds can be estimated. System identification techniques ${ }^{5}$ can be applied to displacement or acceleration data to deduce the values of these or other equivalent empirical coefficients required to calculate flutter speeds.

\section{PROBLEMS WITH MEASUREMENT OF DISPLACEMENT}

For long span bridges, certain practical difficulties arise for the direct measurement of lateral and vertical displacement of the bridge where it is largest i.e. at the centre of the longest span. Such movements can be of the order $1 \mathrm{~m}$ and are a combination of dynamic (modal) response and quasi-static or sub-modal response due to slowly varying loads such as traffic or wind pressure.

The lack of suitable stable locations to use as datum points precludes the use of conventional, contacting displacement transducers, such as pull-wire potentiometric devices, although these can be used to monitor the smaller displacements at expansion joints and other mechanical connections.

A limited amount of displacement information can be derived from servo-type accelerometers as illustrated in Fig. 3. A measure of dynamic vertical and lateral displacements can be obtained by double integration of time or frequency domain information. The latter is equivalent to simply dividing amplitude spectral values by $-\omega^{2}$, where $\omega$ is angular frequency. For that part of the signal close to DC $(\omega \rightarrow 0)$ this can result in unrealistic large values. For time histories, digital high pass filtering is usually necessary to remove the low frequency information and prevent instabilities in the baseline correction algorithm ${ }^{6}$. This is a particular problem for lateral motion which has significant components at very low frequencies.

Referring to Fig. 3, a servo accelerometer (signal a3) sensing horizontally detects both rotational displacement $\varphi$ and horizontal acceleration $\ddot{x}$. At $\mathrm{OHz}(\mathrm{DC})$ the signal represents static rotation and at frequencies sufficiently high to exclude all quasi-static rotation the 
signal is mostly due to horizontal acceleration. Between the extremes, the signals are only partially separable, and interpretation depends on good judgement. Rotational acceleration $\ddot{\varphi}$ can be obtained from the difference of signals al and a from vertically aligned accelerometers at opposite side of the rotating deck, or from angular acceleration sensors, and this could help in separating out the components of the horizontal servo accelerometer signals. Alternatively, quasi-static rotation could be measured by electronic level, gyroscope or plumb-line ${ }^{7}$.

There are other forms of cross-coupling inherent in accelerometers ${ }^{8}$, added to which are errors due to signal noise, drift and thermal stability so displacement data derived from accelerometers have to be interpreted carefully. 


\section{VISUAL TECHNIQUES FOR MEASURING DISPLACEMENT}

Visual techniques offer ideal means of measuring static displacements, since mechanical cross-coupling and most other effects discussed above do not arise. Surveying techniques could be used to provide very sparsely sampled measurements, but where the need for displacement data is not limited to sparse static values an automated system is required. There is then no need to install accelerometers and interpret the total output of these devices as the sum of all the effects described above.

There have been several notable uses of visual dynamic displacement measurement techniques on large structures. At the Tagus River Suspension Bridge in Lisbon 9 telescopes controlled by servo-motors were used to track infra-red lamps on the main span of the bridge while at the CN Tower ${ }^{10}$ a servo-controlled tracking carriage at an upper level was used to track a laser beam pointing vertically upwards from ground level. Laser beams have been used at the Foyle Bridge ${ }^{11}$ where their images on target screens were tracked by a stationary camera. A system employed as part of a technical assessment of the Forth Bridge ${ }^{\mathbf{1 2}}$ relied on location of the brightest part of a video image, which was arranged to be a light source. The systems employed in these applications required separate instruments for each target object being tracked and relied on a very specific form of artificial lighting on or in the structure. These systems are rather specific to their application, whereas an alternative visual system ${ }^{\mathbf{1 3}}$ developed by an Italian institution (ISMES), also used in the Humber Bridge study described here, has been used successfully to track the movement of power transmission cables and of masonry buildings. The ISMES system uses a telescope sighted on a linear image of high contrast (e.g. a neon strip) together with image intensity thresholding software to determine a single displacement coordinate.

Laser vibrometers are commercially available but these have safety considerations, are restricted in range and work in the longitudinal axis which is not practical for the applications described above, and systems are available ${ }^{14}$ which use video recordings of moving objects to reconstruct three-dimensional coordinates time histories (trajectories).

\section{VISION SYSTEM}

\section{The transputer}

The availability of transputer-based image processing equipment now makes tracking (determination of the trajectories) of multiple objects in a very wide range of applications a viable proposition at costs which are not prohibitive. This is because the transputers can work in parallel, each performing specific functions e.g. the tracking of a single target. Such an arrangement can be scaled up to use as many transputers as there are targets to be tracked. A transputer is a special purpose 
microprocessor developed by INMOS Ltd. The transputer chip comprises a central processing unit, memory, chip management circuitry and, most important, four high speed serial data links. These links allow the transputer to communicate with four other transputers, facilitating parallel processing operations. Many transputer topologies can be created and optimised for particular parallel processing schemes.

\section{Vision system overview}

The vision system described briefly in this paper and in detail elsewhere ${ }^{15,16}$ was developed initially to measure two-dimensional structural displacements of up to three objects by tracking the motion of representative object features in a plane transverse to the optical line of sight.

Video pictures or frames are produced at a rate of 25 per second by UK standard video cameras and the system operates by digitising these frames into a rectangular grid of picture elements or 'pixels'. Each pixel contains a digital value of image intensity, with values representing grey levels varying from BLACK $(0)$ to peak WHITE (255). An object in a frame will exhibit a particular pattern of pixel values or grey levels.

The EERC system employs a template correlation approach to track the objects. The user first identifies the object in the first video frame by means of a cursor and the system then constructs a 12 pixel by 12 pixel rectangular template centred on the cursor. This template defines the features of the object. For subsequent frames the object is located by correlating the template with the new digitised frame, as described in detail in subsequent sections.

Template correlation tracking was used in preference to the simpler contrast based schemes, as the latter technique can become easily confused, particularly when the target is not a specially arranged light source but an available structural feature. An important feature of the system is a trajectory prediction algorithm which speeds up the the tracking process thus increasing the maximum manageable object velocity.

\section{System Requirements}

The idea for the vision system originated from a requirement for a measuring tool during earthquake shaking table testing of structural models, in the laboratory. The system would be an alternative to contacting displacement transducers and would be able to define mode shapes by tracking multiple points. Although the system has been used in this application, principally in the developmental stages, it is in fact much better suited to monitoring of large structures where displacements are larger and slower and where there is no real alternative for measurement. 


\section{System Hardware}

Transputers are ideal vehicles for the development of a real-time processing system since a single transputer is capable of performing complex image processing tasks at video frame rate $(25 \mathrm{~Hz})$. The Bristol vision system is a transputer network hosted in a standard personal computer (Tandon PCA70) and is summarised in Fig. 4. It comprises a master transputer (running process 'host.track') which controls three 'slave' transputers (running processes 's.track'), all mounted on a motherboard (Quintek Fast9) in the PC. A fifth transputer (running process 'track') controls the operation of a video frame grabber (Quintek Harlequin) which digitises each video frame.

\section{Object Tracking}

The frame grabber obtains a $256 \times 256$ pixel digitised video image from each frame of the input (a video camera or video tape) and a sub-image of this that contains (or is expected to contain) an image of the appropriate target is passed to the respective slave transputers. The correlation algorithms running in the slaves locate the new position of the target feature in each image and pass the pixel coordinates back to the master transputer for display on a monitor together with the video image, and for storage on the computer disk. The number of objects which can be tracked could be increased by using more transputers; up to 8 slaves could be installed using this particular hardware implementation.

The tracking procedure executed by the slave processors finds the position of the relevant object feature in a sequence of input images by means of the repeated application of a template matching operation. Templates of the user-selected object features are extracted from the initial frame in the sequence and the positions of these features in subsequent images are determined by the slave processors which correlate the templates with the image. The best measure of correlation was found to be minimum least squares error between the pixel intensities of the template and the image for possible matches of the template to the video frame.

The chosen method of locating the position for the minimum was by scanning over all possible template positions. Other possible methods were investigated such as scanning over finer and finer grids or using gradient search algorithms to locate minima of the least squares function, or 'correlation surface'. The former method would not work if the template size compares with the coarsest grid resolution and the latter is not guaranteed to locate the global minimum.

In the time available for correlation by the chosen method only a subset of the frame, termed a 'search window' can be scanned for target location and the search window is centred on the last known target position (Fig. 5a). This search window is the sub-image passed to the slave transputer. The overall procedure operates at $25 \mathrm{~Hz}$ 
frame rate and has a maximum permissible object velocity of 150 pixels/second (6 pixels per frame at $25 \mathrm{~Hz}$ ) for tracking without the aid of predictive techniques. The object positions are determined to a spatial resolution of $0.4 \%$ of field of view in this application, which can be improved by techniques of sub-pixel interpolation. The physical significance of the tracking rate and resolution relate to the field of view which depends on the optical configuration.

\section{Position Prediction}

The tracking capability is limited by the time taken to obtain a correlation of the target template within the search window; for small templates this depends principally on the size of the search window, and the maximum trackable motion between video frames is limited by the width of this search window (Fig. 5a). If the processor is able to predict to a given tolerance where the target will be in successive frames the maximum inter-frame displacement can be significantly increased (Fig. 5b). Each of the two components $x, y$ of the trajectory can be approximated by a given function, such as a polynomial, over a certain number of time steps (m) and an extrapolation of the function to predict the subsequent displacements $\mathrm{x}_{\mathrm{p}}, \mathrm{y}_{\mathrm{p}}$ can be used to locate the optimal position for the next correlation search window. For the case of approximating the components of the trajectory with polynomial functions, the extrapolation reduces to the evaluation of a weighted sum of immediate past values. One successful form of polynomial approximation finds a least squares fit of a lower order polynomial to more than the minimum number of data points.

Although the fairly low rates of change involved in the Humber Bridge motion do not constitute a severe test of predictive techniques and the polynomial approach works well enough with the bridge motion, an adaptive predictor was eventually employed in the vision system for more robust tracking of less amenable trajectories.

The adaptive predictor effectively makes an autoregressive model of the position sequence by modelling the trajectory in the frequency domain, rather than in the time domain so that a much wider range of signal types may be approximated. A set of non-recursive prediction weights are calculated at each time step to provide the optimum prediction. In a severe test of the algorithm using a synthetic motion signal the use of the adaptive predictor resulted in an approximate tenfold increase in velocity capability ${ }^{16}$.

\section{Optical system and target}

The system is not tied to a specific optical configuration, but the system used at Humber employed a monochrome CCD (charge coupled device) video camera fitted with a $\mathrm{f} / 5.6$ lens (either $150-600 \mathrm{~mm}$ zoom or $800 \mathrm{~mm}$ prime). The camera was set to strobe mode using a $1 / 1000$ second electronic shutter to reduce motion blur and 
recordings of the view of the target were made on 60-minute U-matic professional quality tapes.

The video images were taped and processed subsequently in order to preserve the original data and to allow for interrupted tracking. The vision system was later used to analyse the tapes.

Because the main span of the Humber Bridge has few distinct planar features other than service gantries, a more suitable target was arranged in the form of a 'roundel' arrangement of concentric matt-black and reflective rings on a $400 \mathrm{~mm}$ square board clamped to the bridge railings at centre span. The roundel is an ideal target since it has clear two-dimensional edges and is rotationally invariant so that there is no error or allowance due to template rotation.

With the $800 \mathrm{~mm} \times 2$ focal length lens, the vertical field of view (FOV) obtained at Humber at a distance of $710 \mathrm{~m}$ from the target was approximately $2.17 \mathrm{~m}$. The vision system digitises 0.89 of this, with a $1: 1$ aspect ratio, giving equal horizontal and vertical FOVs of $1.94 \mathrm{~m}$.

The exact scale for the images and the displacements could be calculated using exact values of the parameters of the optical system, namely object distance and horizontal offsets, lens focal length and vertical height of the active area of the video camera sensor array $(4.79 \mathrm{~mm})$. An alternative is to use the image size of a component of known physical dimension, namely the diagonal of the target board. The latter method was adopted, giving a calibration of $7.56 \mathrm{~mm} / \mathrm{pixel}$ for the $710 \mathrm{~m}$ range.

Figure 6a shows the roundel target clamped to the East side of the bridge during final measurements in phase 2 (the larger board is a target for the ISMES system) and Fig. $6 \mathrm{~b}$ shows a typical digitised image of the target in its usual location attached to a service gantry under the bridge deck, in the position marked ' $x$ ' on the sectional view of Fig. 2.

\section{MONITORING PROGRAMME}

The monitoring of the bridge was performed in three phases. Firstly, a short term pilot study was undertaken by the EERC, with measurements being made during one week in October 1989. In this phase (phase 1), anemometer signals and mid-span accelerations were recorded using an analog tape recorder, concurrently with the video recording of the bridge motion, obtained using the zoom lens to allow some latitude in setting up different camera/target configurations. Due to the vertical curvature of the bridge deck, there is no unobscured line of sight between deck level at the tower and the mid-span position so the camera was located at the pier level, approximately $36 \mathrm{~m}$ below the deck height at mid-span. This exploratory study proved 
the feasibility of the intended measurement technique, and also allowed practical difficulties such as camera shake to be identified and dealt with.

Phase 2 was subsequently conducted over the period of March to May 1990 as part of a monitoring program set up by Politecnico di Milano. Parameters such as temperature, bridge deck accelerations and displacements, wind speed and wind direction were monitored by Politecnico di Milano ${ }^{2,17}$ and a selection of these signals, plus signals from a cup and vane anemometer independently installed by the EERC were recorded on write-once-read-many (WORM) optical disk cartridges. Based on experience from phase 1 and to facilitate lining up the prime lens with the target, the lens was mounted at ground level on a purpose-built alt/azimuth alignment jig, bolted to a concrete plinth housed within a weather-proof cabin and located between the columns of the Hessle Tower.

Approximately 60 hours of bridge motion were video taped for subsequent analysis using the vision system ${ }^{1}$. These measurements were made in order to verify and complement those obtained from three opto-electronic displacement transducers employed by Politecnico di Milano ${ }^{13}$.

To minimise data storage requirements, position samples were logged every 6 th frame using the tracking system, giving a sampling rate of $4.17 \mathrm{~Hz}$. Because the Nyquist frequency for the $4.17 \mathrm{~Hz}$ sampling rate is well above the frequency of any visually resolvable vibration mode there is no problem of aliasing; the measurement capability of the vision system is not frequency dependent. The positional data were saved in ASCII files for subsequent analysis and comparison with the other parameters measured at the same time.

In phase 3 , in the first half of 1991, a small number of anemometer, accelerometer and potentiometer signals from Politecnico di Milano instrumentation were digitised by EERC ${ }^{\mathbf{1 8}}$ and recorded on WORM optical disk cartridges to increase the range and statistical accuracy of selected response parameters beyond that available with phase 2 data alone. The vision system was not used in phase 3.

\section{RESULTS AND DISCUSSION}

Of the 60 hours of bridge motion recorded during phase 2 of the monitoring programme, a total of 49 hours have been analysed. Some of the recordings were unsuitable due to insufficient contrast and excessive noise, caused, for example, by haze or other atmospheric effects. Full analyses of the results from the monitoring exercise are to be found elsewhere ${ }^{2,5,17,18}$, but results relevant to the vision system alone are presented here. 


\section{Displacement Time Histories}

Fig. 7 shows sample displacement time histories for the bridge at mid-span, obtained from the analysis of a video recording of motion during high winds up to 'strong gale' (force 9 on the Beaufort scale). The displacement is resolved into lateral and vertical components (Figs. 7a,b), and is shown together with the normal component of the wind velocity perpendicular to the longitudinal axis of the bridge (Fig. 7c). The positive sense for the measurements corresponds to a lateral displacement from West to East, vertical displacement upwards and wind blowing from the West in the respective figures. This convention corresponds to the $-\mathrm{x}$ and $+\mathrm{z}$ directions indicated in Figure 2.

Figure 7 shows that each component of the mid-span motion has a strong oscillatory component, superimposed on a very low frequency movement, or drift, of the deck. The fundamental vibration modes corresponding to the oscillations have frequencies of approximately $0.06 \mathrm{~Hz}$ and $0.12 \mathrm{~Hz}$, for lateral and vertical motion respectively. A correlation between the transverse wind component and the movement of the deck can be seen from Figure 7, particularly for the lateral displacement. For a wind from the West, the bridge deck tends to move to the East and downwards.

Figure 8 shows the vertical displacement time history obtained during a period of calm weather. The significant vertical motion is almost entirely due to heavy vehicles; Fig. 9 compares the influence line of centre span vertical displacement with a period at the start of the displacement time history, due to a vehicle of unknown weight. The influence line has been calibrated using the ISMES optical system and a vehicle of known weight. These influence line 'dips' are strongest at peak times for heavy goods vehicles (HGVs), for cars the effect is not so marked. Visual measurements were obtained mostly at weekends when HGV traffic is minimal.

A further effect on deck displacements is the thermal expansion of the structure as the bridge warms up during the day which results in a diurnal variation of vertical and rotational deck displacements. With the aid of a solid-state temperature probe installed on one of the main cables it has been established ${ }^{\mathbf{1 7}}$ that the centre span displaces downward approximately $0.064 \mathrm{~m}$ per ${ }^{\circ} \mathrm{C}$ increase in main cable temperature.

The bridge deck excursion, i.e. the total movement between position extrema, during the particular hour of Figure 7 was $0.45 \mathrm{~m}$ both laterally and vertically. The displacement time history values are with respect to an arbitrary datum (depending on lens alignment) but where the lens alignment has been left undisturbed, position comparisons can be made between tapes to within a few centimetres, and excursions in the region of $0.9 \mathrm{~m}$ have been observed from tapes recorded over a period of two days. 


\section{Relationship of response and wind speed}

Sufficient data have been collected to examine the relationship of steady lift and drag forces with steady wind speed. Fig. 10 shows time histories of vertical displacement, wind speed and lateral displacement during a 25 hour period over a weekend of variable South-Westerly to Westerly winds. The values are determined as 64 -second averages. The lower of the pair of traces in Fig. 10a,c are data obtained from the ISMES optical system which was being set up at the time; the upper intermittent lines are the vision system data obtained from 1-hour recordings. The datum points of the displacement axes are entirely arbitrary and the vision system data has been offset $0.1 \mathrm{~m}$ from the ISMES data to allow comparison.

The wind speed time history as shown is the normal component $V \cos \theta$ where $\theta$ is the horizontal angle of incidence (see Fig. 2: $0^{\circ}$ is normal to the span) which varied between $-60^{\circ}$ and $0^{\circ}$. The supposition is that wind loads are proportional to this component of the wind. The cup anemometer has been calibrated in the open section wind tunnel of the University of Bristol Aerospace Engineering Department, and the wind speed values were obtained at a height of $8 \mathrm{~m}$ above the centreline of the deck with no adjustment to represent free stream speed.

Fig. 11 shows how vertical and horizontal displacements correlate with V $\cos \theta$. A clear parabolic relationship is visible in Fig. 11a for horizontal displacement. For vertical displacement (Fig. 11b) the relationship is less clear principally because of variations in temperature and to a much lesser extent road traffic consisting of a few hundred passenger cars crossing per hour.

Using the parabolae fitted to the data as shown in Fig. 11, approximate values of lift and drag coefficients can be derived as follows.

$$
\begin{aligned}
& \mathrm{F}_{\mathrm{y}}=1 / 2 \rho \mathrm{V}^{2} \mathrm{BC}_{\mathrm{L}} \text { and } \mathrm{F}_{\mathrm{y}}=\mathrm{k}_{\mathrm{y}} \mathrm{y} \ldots \ldots \ldots \ldots \ldots \ldots \ldots \ldots \ldots \ldots \ldots \ldots \ldots \ldots \ldots \ldots \ldots \ldots \ldots \ldots \ldots \ldots \ldots \ldots \ldots \ldots \ldots \ldots \ldots \ldots \ldots \ldots \\
& \mathrm{F}_{\mathrm{X}}=1 / 2 \rho \ldots \ldots \ldots \ldots \ldots
\end{aligned}
$$

where B is the reference chord length shown in Fig. 2 (taken as total width of the deck, $28.5 \mathrm{~m}) \mathrm{F}_{\mathrm{y}}, \mathrm{F}_{\mathrm{x}}$ are vertical and horizontal forces per metre length of span. ky and $\mathrm{k}_{\mathrm{x}}$ are vertical and horizontal forces distributed uniformly along the suspended spans required for centre span deflections of $1 \mathrm{~m}$.

Rearranging 2 and 3 ,

$$
\begin{aligned}
& C_{L}=\frac{k y}{1 / 2 \rho B} \cdot \frac{y}{V^{2}} \\
& C_{D}=\frac{k x}{1 / 2 \rho B} \cdot \frac{x}{V^{2}}
\end{aligned}
$$


Values of $\mathrm{ky}_{\mathrm{y}}=7.58 \mathrm{kN} / \mathrm{m}^{2}$ and $\mathrm{kx}_{\mathrm{x}}=0.99 \mathrm{kN} / \mathrm{m}^{2}$ were determined by using the finite element model $^{19}$ to determine vertical and lateral response of the deck to a uniformly distributed load and values of coefficients of $x / V^{2}$ and $x / V^{2}$ were derived from the parabolae shown in Fig. 11. Substituting these values in equations 4 and 5 leads gives:

$$
\mathrm{C}_{\mathrm{L}} \approx 0.35 \text { and } \mathrm{C}_{\mathrm{D}} \approx 0.067 \text {. }
$$

compared with values derived from the original section model wind laminar flow tunnel studies $^{20}$ :

$$
\mathrm{C}_{\mathrm{L}}(\alpha=0) \approx 0.26 \text { and } \mathrm{C}_{\mathrm{D}}(\alpha=0) \approx 0.078
$$

The lift and drag co-efficients vary with angle of attack $\alpha$ which depends on deck configuration and the wind vector so the values given above are averages for $\alpha=0$.

\section{Accelerometer Measurements}

During the monitoring programme, accelerometers were used to measure the vertical acceleration at either side of the bridge deck at the mid-span position. Lateral acceleration was also recorded there using an inclinometer which was originally intended to measure deck rotation. The west mid-span vertical acceleration record corresponding to the sample optical displacement time history of Fig. 7 was integrated ${ }^{5}$ numerically and the comparison is shown in Figure 12.

It can be seen from Figure 12 that there is a correspondence between the modal vibration components in the two traces. When the two plots are overlaid and shifted, the peak-peak amplitudes are seen to be in close agreement. The lower frequency trend of the displacement has, however, been lost in the integration which necessarily uses a digital high pass filter. A similar comparison for the lateral motion was not possible, due to the significant and slowly varying rotational component in the inclinometer signals.

\section{Spectral Analysis and dynamic response}

Single-sided amplitude spectra for typical lateral and vertical motion time histories are given in Figures 13 and 14 respectively. These were determined from the discrete Fourier transforms of 32 minute sections of two separate displacement records and represent a resolution of $0.0005 \mathrm{~Hz}$. The frequency values of the indicated spectral peaks were estimated using a least mean squares (LMS) curve fitting procedure which fits the response of a second order system with a spectrally flat input to the displacement spectral peak.

The use of the LMS fitting assumes that the forcing input is constant over the fitted frequency range and that individual spectral peaks are not influenced by adjacent ones. Table 1 below shows good agreement of the displacement resonant frequencies with those obtained from a modal survey of the Humber Bridge ${ }^{19}$. These latter values were obtained by averaging the acceleration spectra of many sampled data sets, to- 
smooth out the effects of variations in the input excitation, whereas the visual data derive from single data sets and have a high variance error.

\begin{tabular}{|l|l|ll|}
\hline \multirow{2}{*}{ LATERAL } & $\begin{array}{l}\text { Frequency from } \\
\text { displacement spectrum } \\
\text { (vision system) }\end{array}$ & \multicolumn{2}{|l|}{$\begin{array}{l}\text { Vibration mode (from } \\
\text { modal survey }\end{array}$} \\
\hline & $0.054 \mathrm{~Hz}$ & L1 & $0.056 \mathrm{~Hz}$ \\
\cline { 2 - 4 } & $0.247 \mathrm{~Hz}$ & $\mathrm{~L} 6$ & $0.260 \mathrm{~Hz}$ \\
\cline { 2 - 4 } & $0.309 \mathrm{~Hz}$ & $\mathrm{~T} 1$ & $0.311 \mathrm{~Hz}$ \\
\hline \multirow{3}{*}{ VERTICAL } & $0.115 \mathrm{~Hz}$ & $\mathrm{~V} 1$ & $0.116 \mathrm{~Hz}$ \\
\cline { 2 - 4 } & $0.158 \mathrm{~Hz}$ & $\mathrm{~V} 2$ & $0.154 \mathrm{~Hz}$ \\
\cline { 2 - 4 } & $0.176 \mathrm{~Hz}$ & $\mathrm{~V} 3$ & $0.177 \mathrm{~Hz}$ \\
\cline { 2 - 4 } & $0.309 \mathrm{~Hz}$ & $\mathrm{~V} 6$ & $\begin{array}{l}0.310 \mathrm{~Hz} / \\
0.311 \mathrm{~Hz}\end{array}$ \\
\hline
\end{tabular}

Table 1 Humber Bridge deck vibration modes

After the fundamental frequency, the amplitude of the higher modes decreases quite sharply, justifying the assumption that there is no resolvable displacement response above the Nyquist frequency for the sampling of the tracking system $(2.08 \mathrm{~Hz})$. The mode shapes for modes L2, L4, L5, V4 and V5 all pass through nodes close to the mid-span position, and would therefore not be expected to be strongly evident in the measurements.

\section{Aeroelastic response}

It has been established ${ }^{\mathbf{1 7 - 1 9}}$ from accelerometer signals that the amplitudes, resonant frequencies and damping values of the bridge deck vibration modes are dependent on the mean speed of the wind exciting the structure. The relationships of modal amplitude and wind speed have been established by integrating power spectral density curves for acceleration response in the region of a resonance, giving mean square modal amplitude as a function of wind speed. If the integration is extended from $0 \mathrm{~Hz}$ to sampling rate the total mean square amplitude is obtained which is equivalent to that which can be determined directly from a time history. Fig. 15 shows the relationship of standard deviation $(\sigma)$ of displacement with wind speed, corresponding to the data of Figs. 10 and 11. The relationship is obscured by the considerable scatter of the $\sigma$ values and judging from Figs. 13 and 14 this is due to the quasi-static motion partly due to wind, partly due to traffic. A very much clearer picture of the relationship of wind and modal response can be (and has been) obtained from accelerometer signals corresponding to periods of low traffic. 
The dynamic response of the bridge can be described in terms of empirical coefficients which are related to the static aerodynamic coefficients and their derivatives. The rotational and vertical displacement and velocity of the deck changes the effective angle of attack of the deck which in turn modifies the moment and lift forces and the result is that lift force is influenced by rotation and moment by translation. The modes of vibration are not then fully de-coupled, particularly at high wind speeds where flutter is the result, while at lower speeds the effects are visible in the altered modal properties (damping, frequency). In order to have a full picture of how this coupling operates and to evaluate the accuracy of the empirical predictions and the extrapolation from model scale (wind tunnel studies) to full-scale it is necessary to have displacement and rotation time histories uncontaminated by mechanical cross-coupling. Visual measurements of displacement appear to be the only reliable means for providing these.

\section{Problems, errors and future developments}

The main difficulties in obtaining trajectories from the video signals relate to the characteristics of the air mass between the target and the camera. It can be shown that the uncertainty introduced into the measurements due to relative atmospheric refraction is negligible under certain assumed conditions. However, more significant errors may have occurred in the realistic situation, as the actual optical behaviour of the air mass during the observations is unknown. Local variations in the air strata may, for example, give rise to effects such as air tremor. These perturbations therefore impose limitations on any optical system operating over large distances. However, video tapes found, from visual inspection, to exhibit such effects to a significant degree were not selected for subsequent analysis using the system. Transient interruption of the line of sight is another potential problem and the system has to recover the target position when this occurs. Future development of the vision system will address these problems and improve the robustness and multi-target capacity of the system.

\section{CONCLUSIONS}

This paper has described the application of a displacement measurement system which operates by visually tracking multiple moving objects in real-time. The use of a transputer network allows the tracking operations to be performed in parallel, and at present up to 3 independent target objects may be accommodated. This capability could, however, be increased by adding more processors to the network.

The use of the system has provided extensive data which could not otherwise have been acquired. These data, in conjunction with concurrent measurements of other relevant physical parameters, have allowed the behaviour of the Humber Bridge under a range of different ambient conditions to be studied. In particular, it has permitted the very low frequency movement of the bridge to be observed. 
The motion of the bridge at centre span is a combination of rotations and translations that are difficult to identify separately from accelerometer measurements alone.

The modal vibration amplitudes obtained have been confirmed by comparison with integrated acceleration signals and data from an independent source (ISMES). A few of the lower deck vibration modes have been identified from spectral analyses of the displacement data, with the resonant frequencies comparing favourably with previously available data.

While visual techniques are essential for identification of very low-frequency performance, accelerometer measurements are more suitable for use in modal investigations, as their higher resolution permits the identification of higher frequency, lower amplitude modes.

In the 1990 measurements only a single target was tracked, and it was only possible to determine the horizontal and vertical translations. In future developments and applications multiple targets and dual cameras will be used to determine rotation and three directions of translation at multiple positions so that the complete behaviour can be understood.

\section{ACKNOWLEDGEMENTS}

The first author gratefully acknowledges the financial support of the UK Science and Engineering Research Council (SERC) through a research studentship. The initial development of the tracking system was performed using equipment supplied by the SERC Transputer Initiative Loan Pool (award reference TR/100). The Humber Bridge monitoring exercise was supported by Stretto di Messina SpA, and the cooperation of the Humber Bridge Board is gratefully acknowledged. The authors are grateful to other EERC staff who helped with the monitoring.

Fig. 2 is reproduced by permission of Thomas Telford Limited ${ }^{\mathbf{1 9}}$. 
14 OXFORD METRICS, VICON 3 dimensional motion and image analysis, Oxford, UK.

15 STEPHEN G.A., DAGLESS E.L., TAYLOR C.A. A visual tracking system for the measurement of dynamic structural displacements, Concurrency: Practice and Experience, Vol. 3, No. 4, p. 357-66, August 1991.

16 STEPHEN G.A. Visual determination of dynamic displacements for structural monitoring. PhD Thesis, University of Bristol Departments of CivilEngineering and Electrical and Electronic Engineering, May 1991.

17 EERC, Humber Bridge monitoring: Digital measurements March-May 1990 and preliminary analysis, Report No. UBCE-EE-90-10, University of Bristol Department of Civil Engineering, July 1990.

18 EERC, Humber Bridge monitoring: Digital measurements February-June, Report No. UBCE-EE-91-3, University of Bristol Department of Civil Engineering, September 1991.

19 BROWNJOHN J.M.W., DUMANOGLU A.A., SEVERN R.T., TAYLOR C.A. Ambient vibration measurements of the Humber Suspension Bridge and comparison with calculated characteristics, Proc. ICE, Part 2, Vol. 83, p. 561-600, September 1987.

20 WALSHE D.E., COWDREY C.F., A further aerodynamic investigation for the proposed Humber Suspension Bridge. National Physical Laboratory Mar. Sci Report R102, June 1972. 


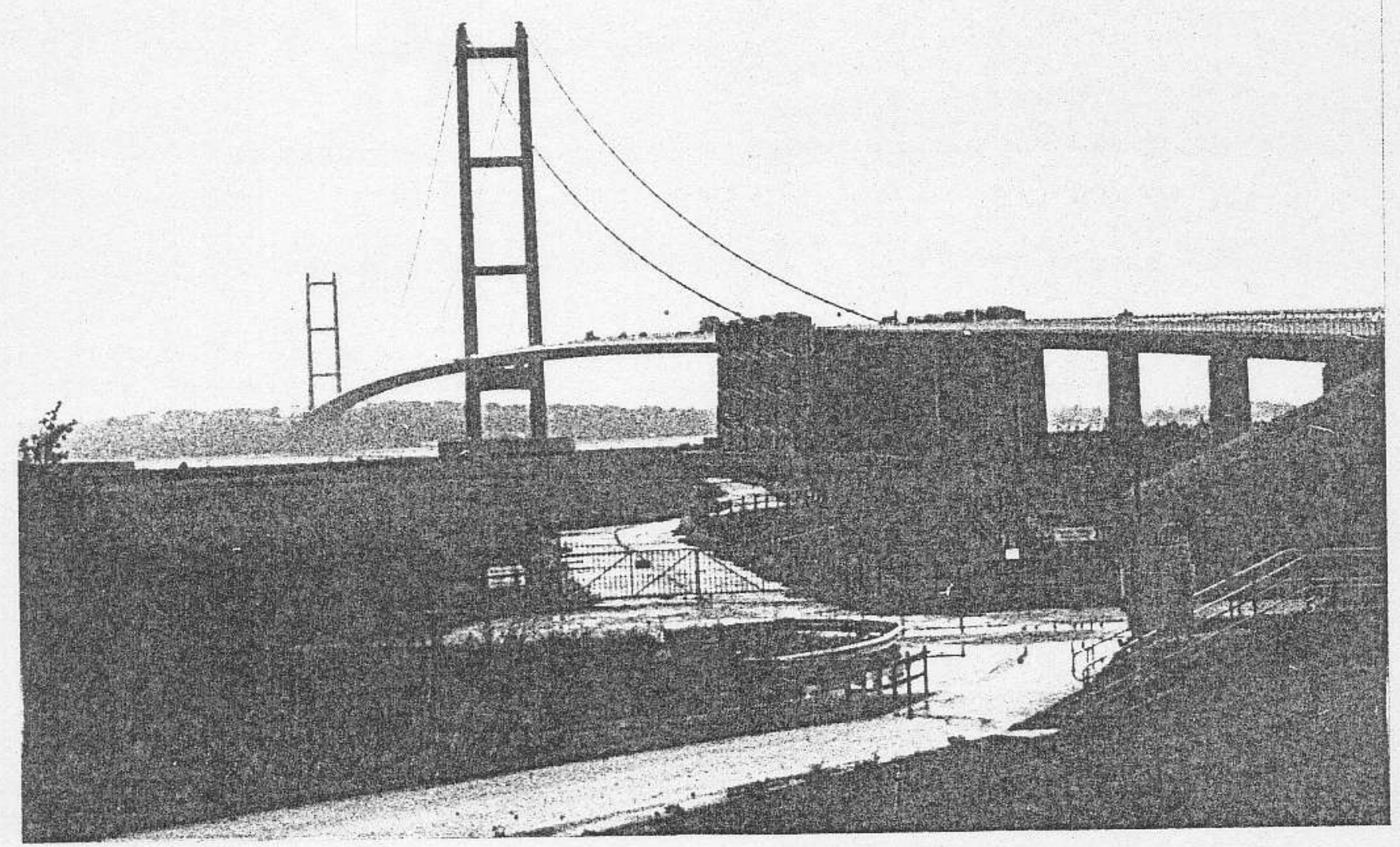

Fig. 1 Humber Bridge

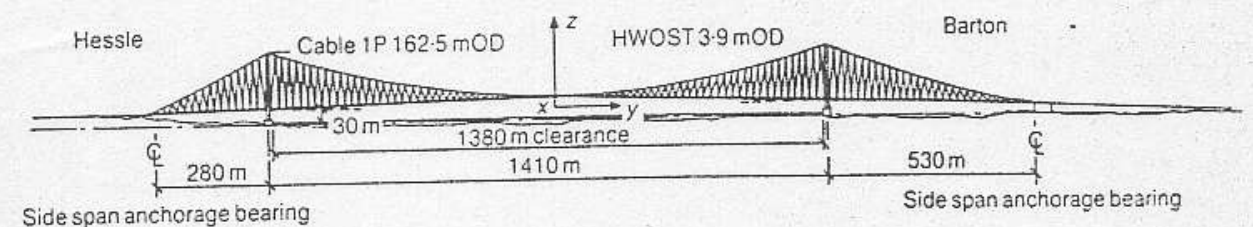

(a)
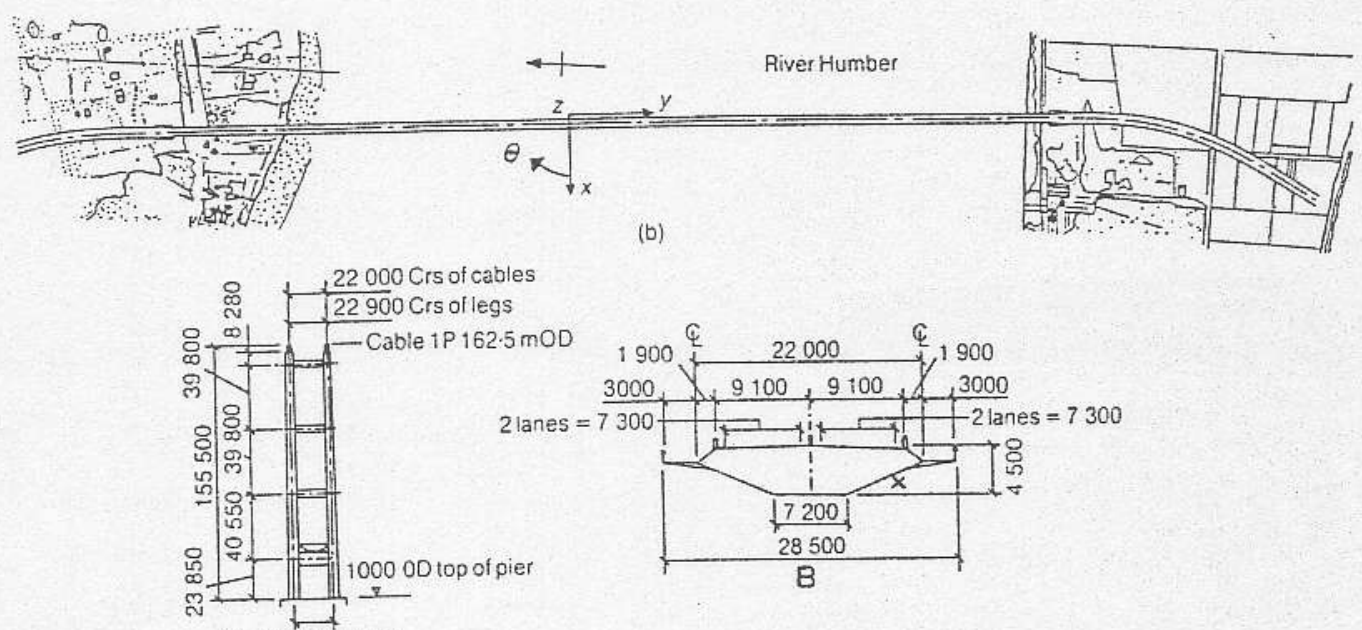

24400 Crs oflegs

Fig. 2 Humber Bridge:- general arangement 


\section{LIST OF FIGURES}

Fig. 1 Humber Bridge

Fig. 2 Humber Bridge:- general arrangement

Fig. 3 Cross section of bridge deck showing measurement of rotation and acceleration with servo accelerometers

Fig. 4 Vision system architecture

Fig. 5 correlation and prediction

a) Tracking by correlation only with search window centred on last location

b) Tracking by prediction

Fig. 6 Roundel target

a) clamped on handrail (ISMES target above)

b) attached to under-deck service gantry, as seen by video camera

Fig. 7 Time histories obtained on Saturday 24/3/1991

a) lateral deflection of deck at midspan

b) vertical deflection of deck at midspan

c) normal component of wind at midspan

Fig. 8 Vertical deflection at midspan due to traffic

Fig. 9 Comparison of influence lines obtained by measurement and analysis:

a) time history at centre span during crossing of vehicle of unknown weight

b) influence line of centre span displacement for vertical load on deck

Fig. 10 Wind and response time histories- 64 second averages

a) lateral displacement

b) normal component of wind $\mathrm{V} \cos \theta$

c) vertical displacement

Fig. 11 Correlation of 64-second average displacements with wind speed

a) $\quad \mu$ lateral displacement

b) $\quad \mu$ vertical displacement

Fig. 12 Comparison of data from video system and processed acceleration signals

a) displacement from video system

b) displacement from integration of accelerometer signal

Fig. 13 Auto power spectrum of lateral deck displacement at midspan

Fig. 14 Auto power spectrum of vertical displacement at mid span

Fig. 15 Correlation of 64-second RMS displacements with wind speed

a) $\quad \sigma$ lateral displacement

b) $\quad \sigma$ vertical displacement 


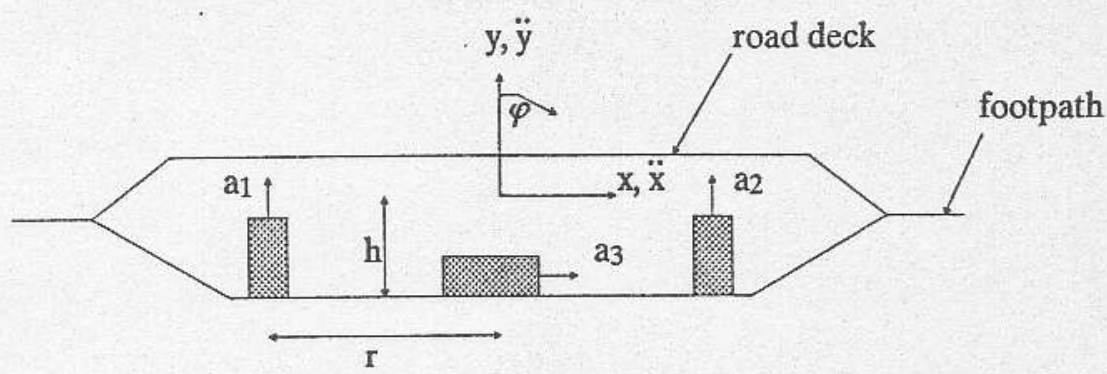

$$
\begin{aligned}
& \mathrm{a}_{1} \approx \ddot{\mathrm{y}} \cos \varphi+\mathrm{r} \ddot{\varphi}+\mathrm{g} \cos \varphi-\ddot{\mathrm{x}} \sin \varphi \\
& \mathrm{a}_{2} \approx \ddot{\mathrm{y}} \cos \varphi-\mathrm{r} \ddot{\varphi}+\mathrm{g} \cos \varphi-\ddot{\mathrm{x}} \sin \varphi \\
& \mathrm{a}_{3} \approx \ddot{\mathrm{x}} \cos \varphi-\mathrm{g} \sin \varphi-\ddot{\mathrm{y}} \sin \varphi-\mathrm{h} \ddot{\varphi}
\end{aligned}
$$

Fig. 3 Cross section of box-girder bridge deck showing measurement of rotation and acceleration with servo-acelerometers 


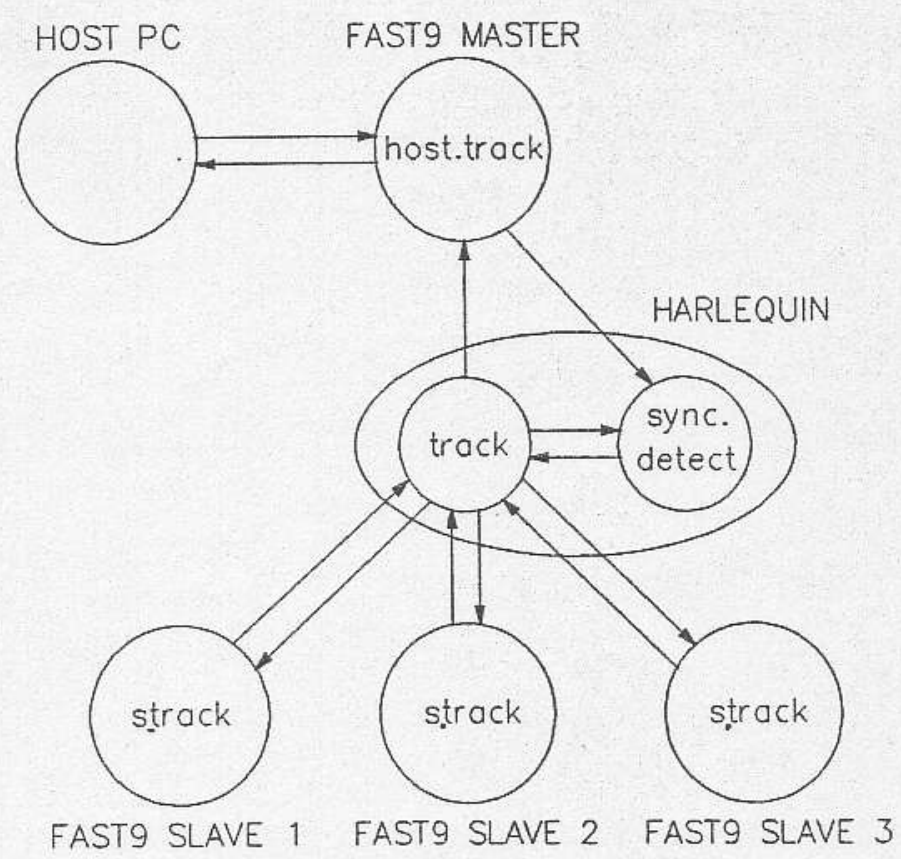

Fig. 4 Vision system architecture 


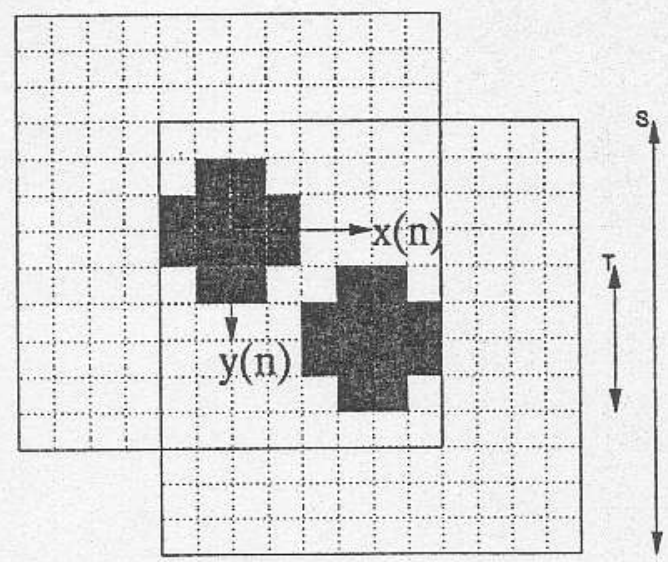

a) Tracking by correlation only with search window centred on last location; Inter-frame displacement $\mathrm{x}(\mathrm{n}), \mathrm{y}(\mathrm{n}) \leq(\mathrm{S}-\mathrm{T}) / 2$; search time $\alpha(\mathrm{S}-\mathrm{T}+1)^{2}$ $\mathrm{S}=$ search window size/pixels; $\mathrm{T}=$ template size/pixels

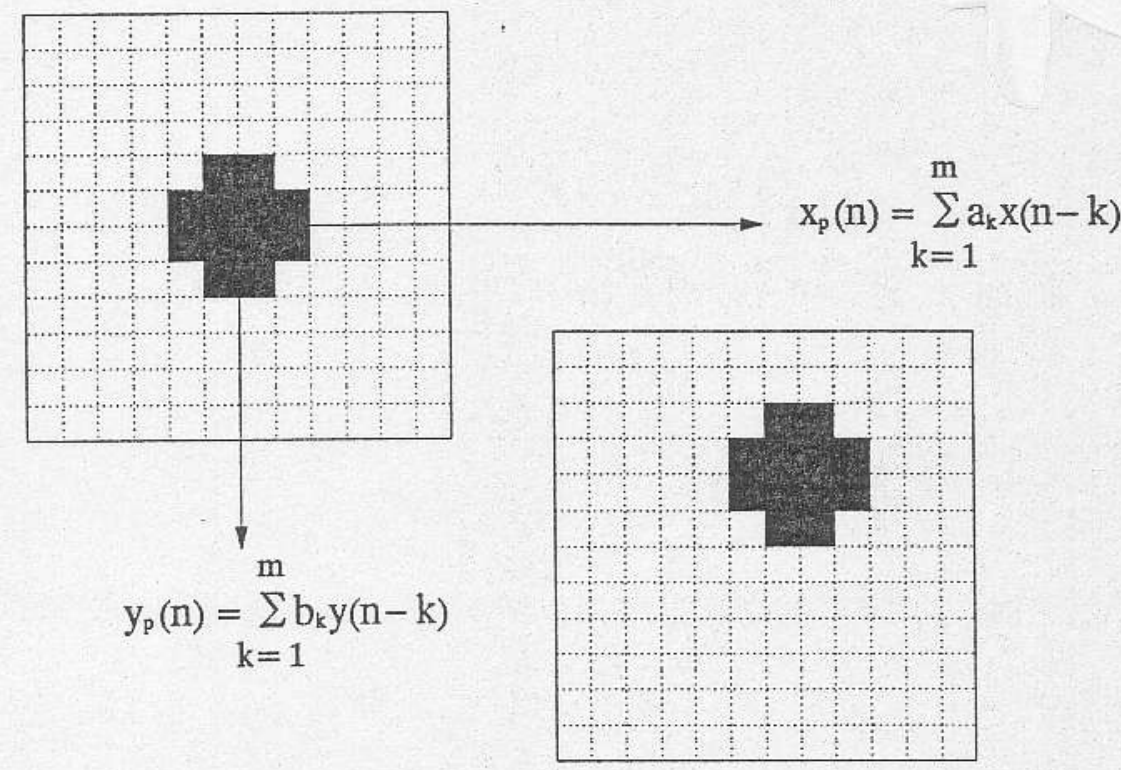

b) Tracking by prediction of $x_{p}(n), x_{p}(n)$ according to weighted sum of previous displacements $x(n-k), y(n-k)$ to locate new search window. $a_{k}, b_{k}$ are not constant for AR predictor.

Fig. 5 Correlation and prediction 

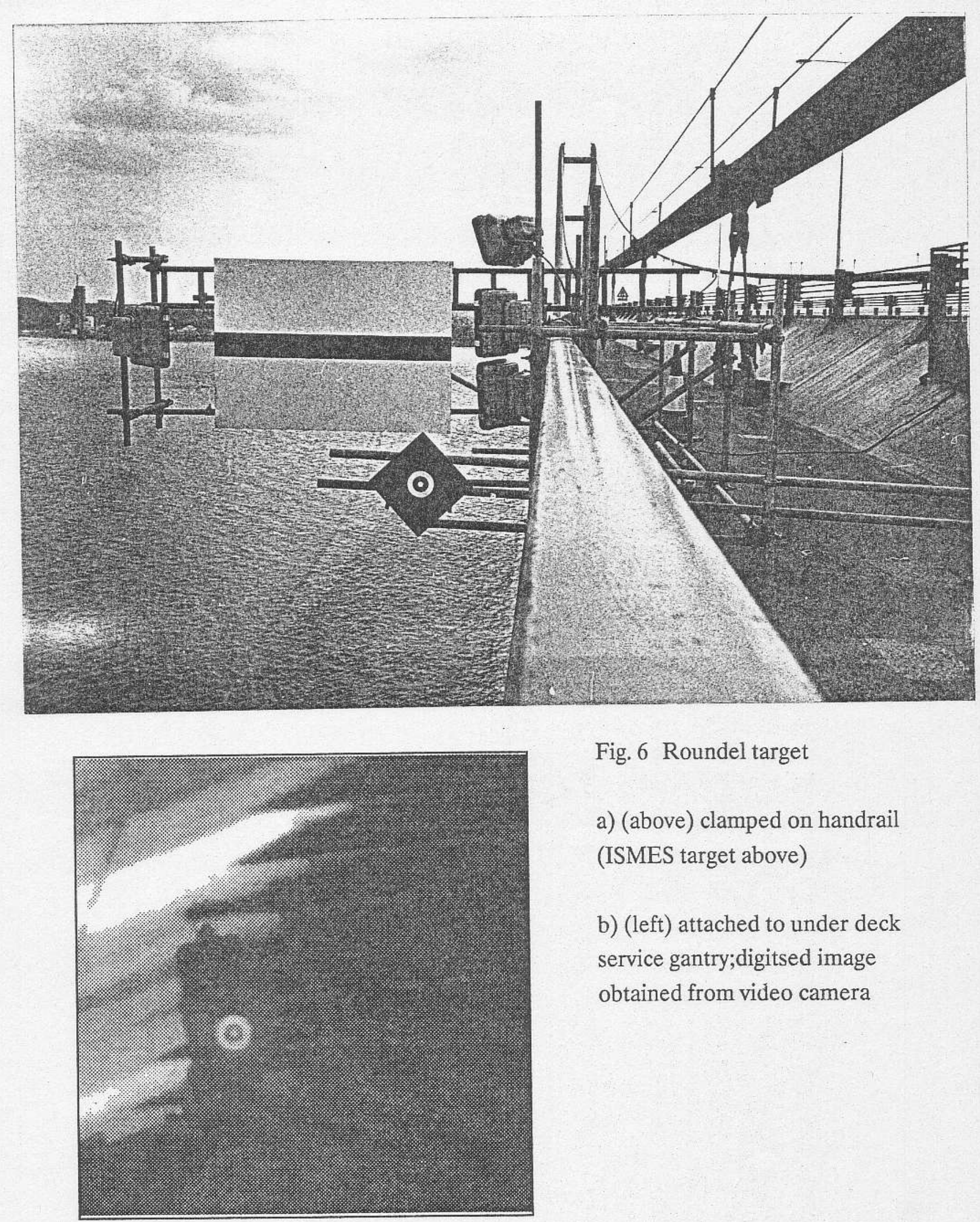

Fig. 6 Roundel target

a) (above) clamped on handrail (ISMES target above)

b) (left) attached to under deck service gantry; digitsed image obtained from video camera 


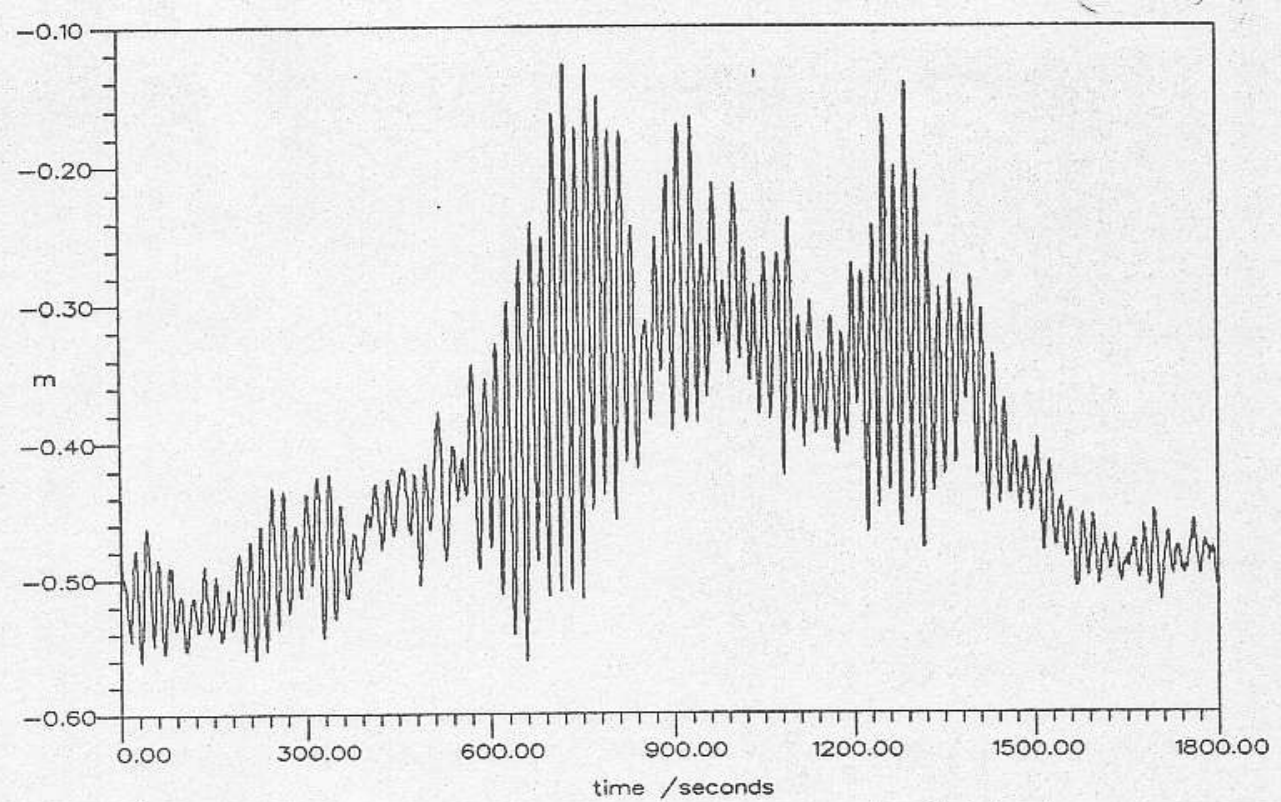

a) Loteral deflection of deck ot midspan. Movement to Eost is +ve

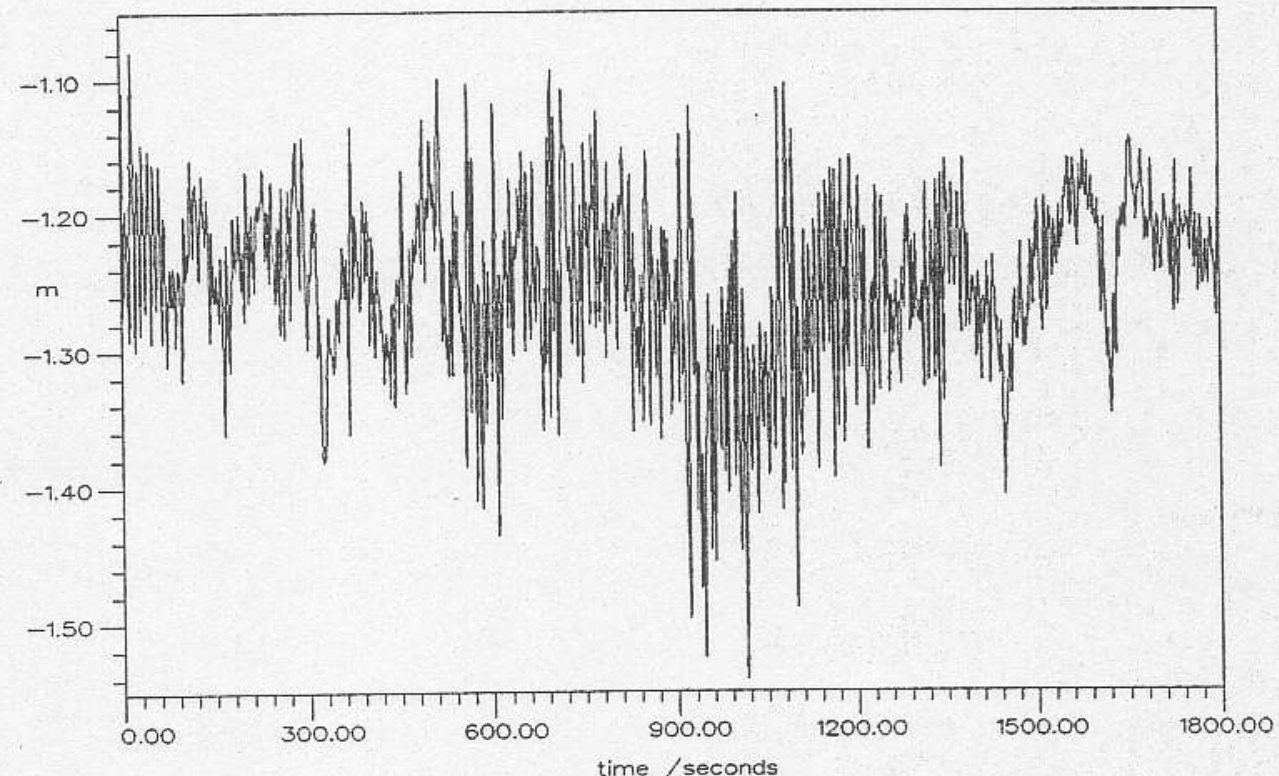

b) Vertical deflection of deck at midspan. Movement upwards is +ve

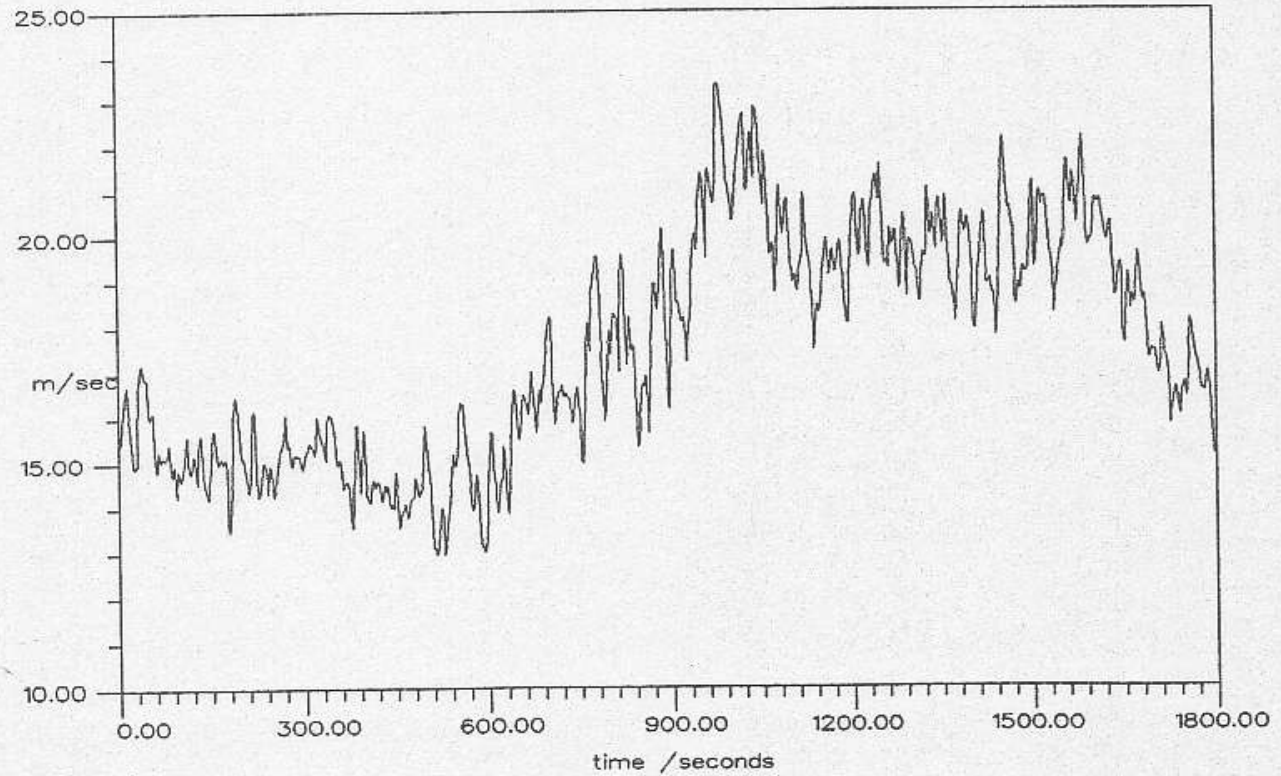

c)

Normal component of wind at mid span. Westerly is +ve

Fig. 7 Time histories obtained on Saturday 24/3/1991 


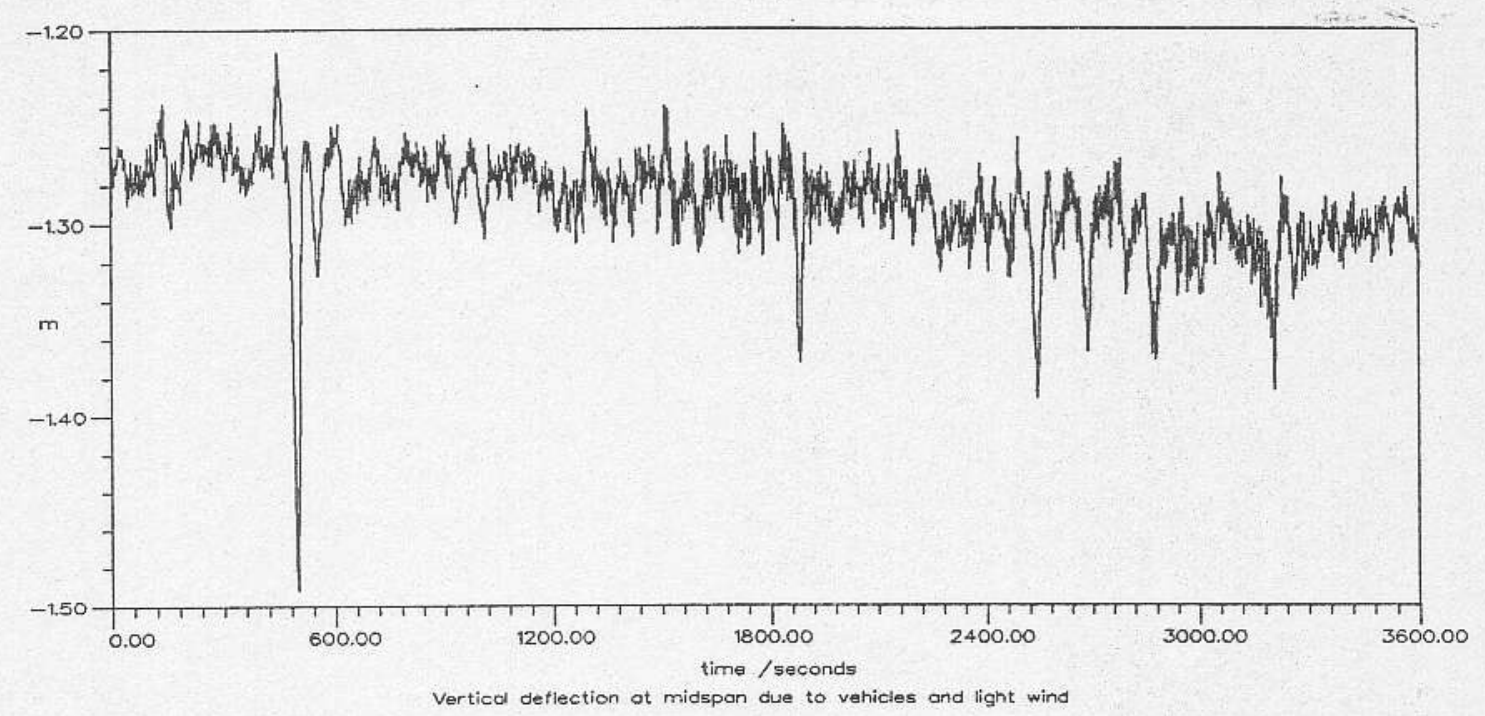

Fig. 8 Vertical deflection at midspan due to traffic 


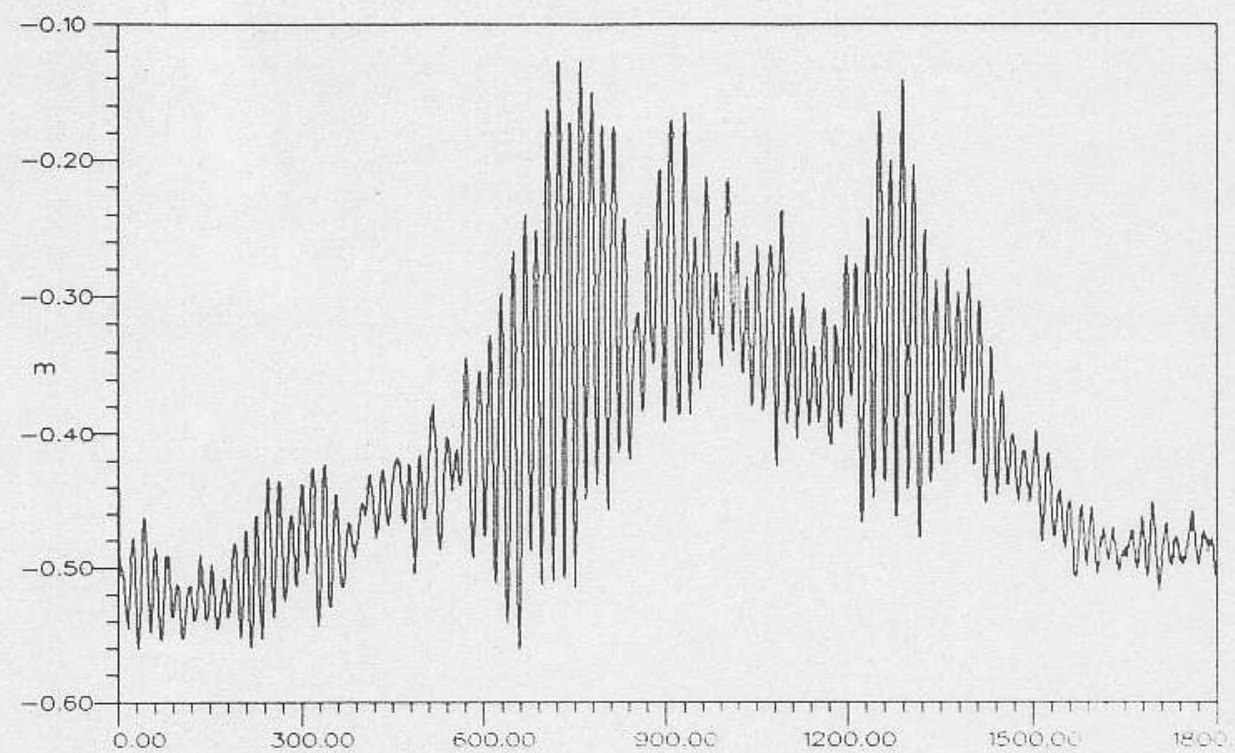

a)

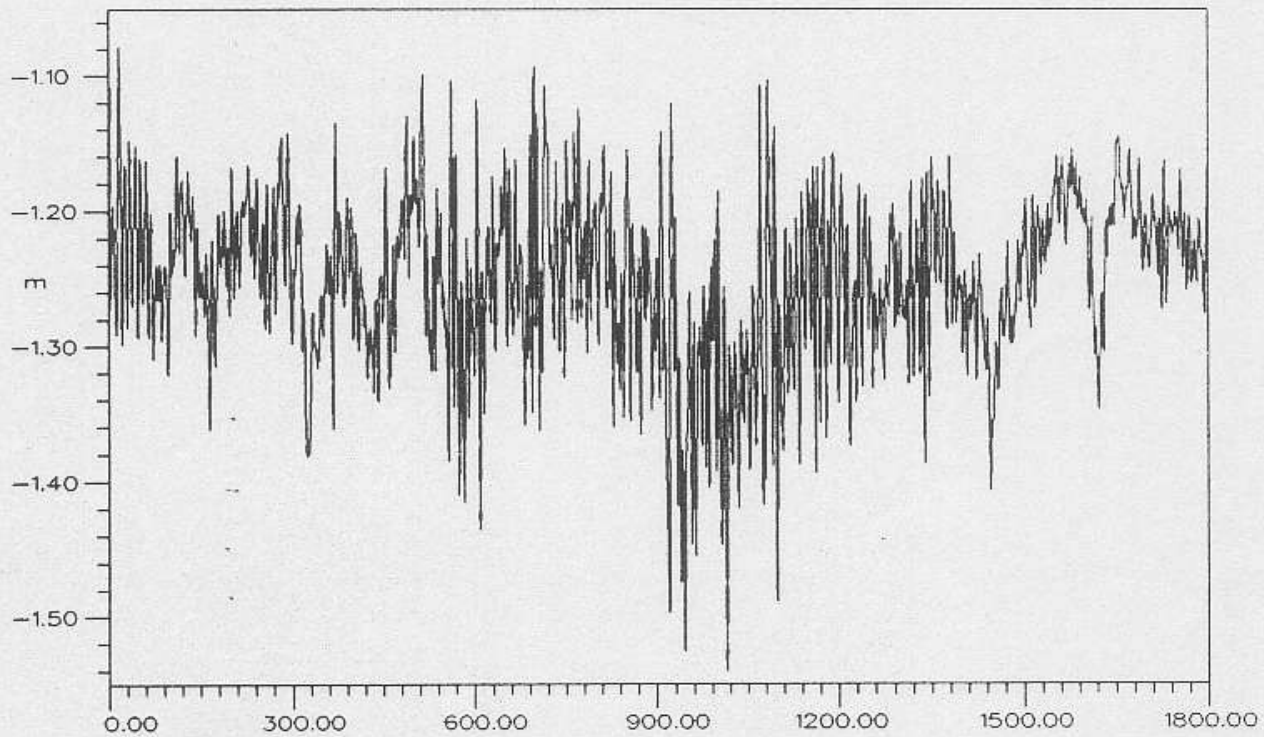

b) time / seconds

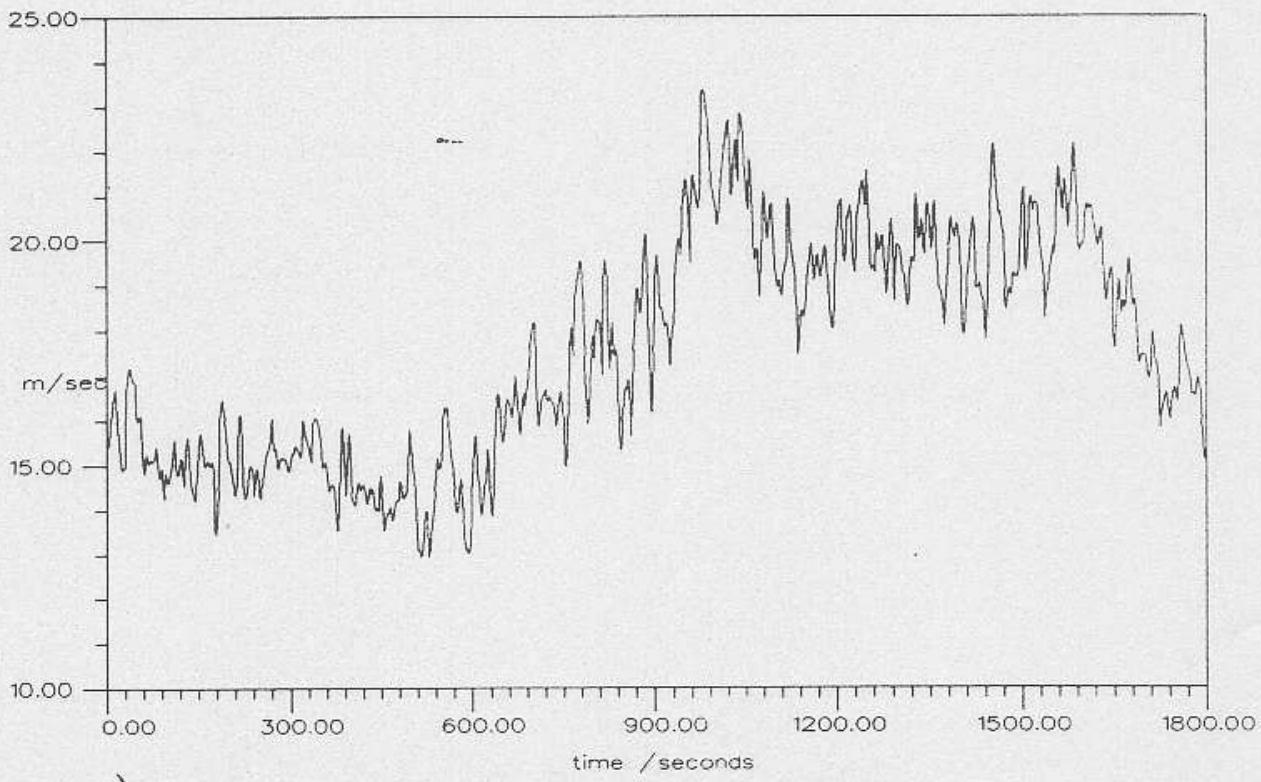

c)

Fig. 9 Time histories obtained on Saturday 24/3/1990 


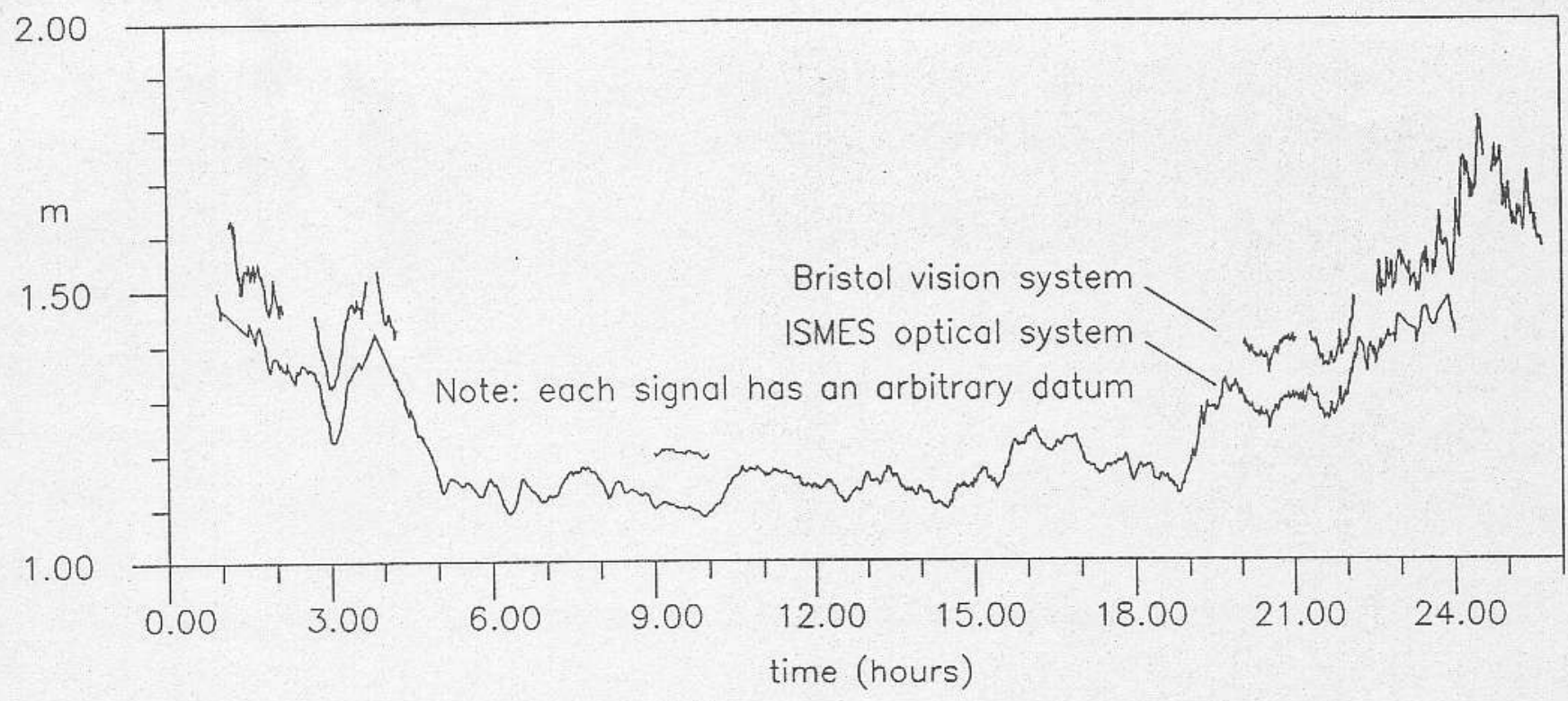

a) lateral displacement
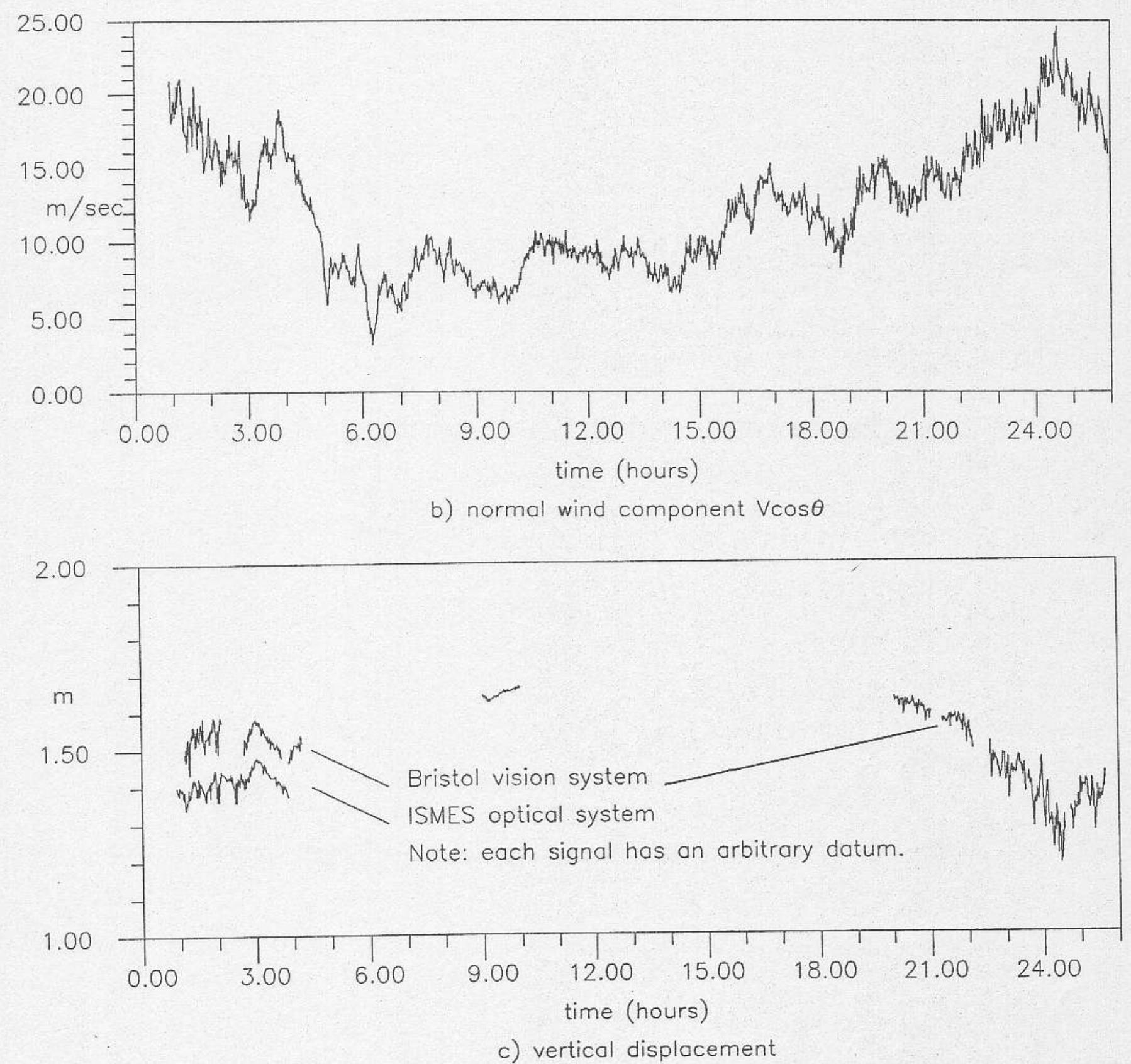

Fig. 10 Wind and response time histories -64 second averages 


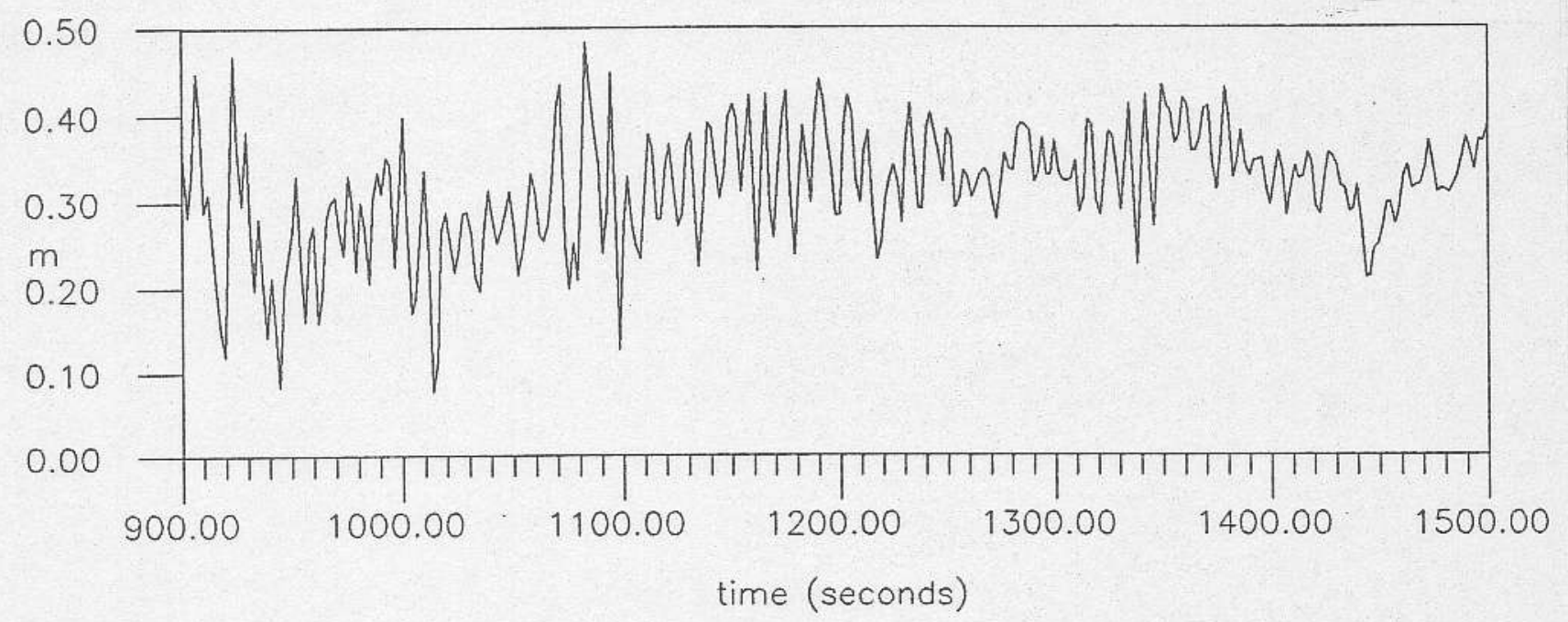

a) vertical time history from vision system

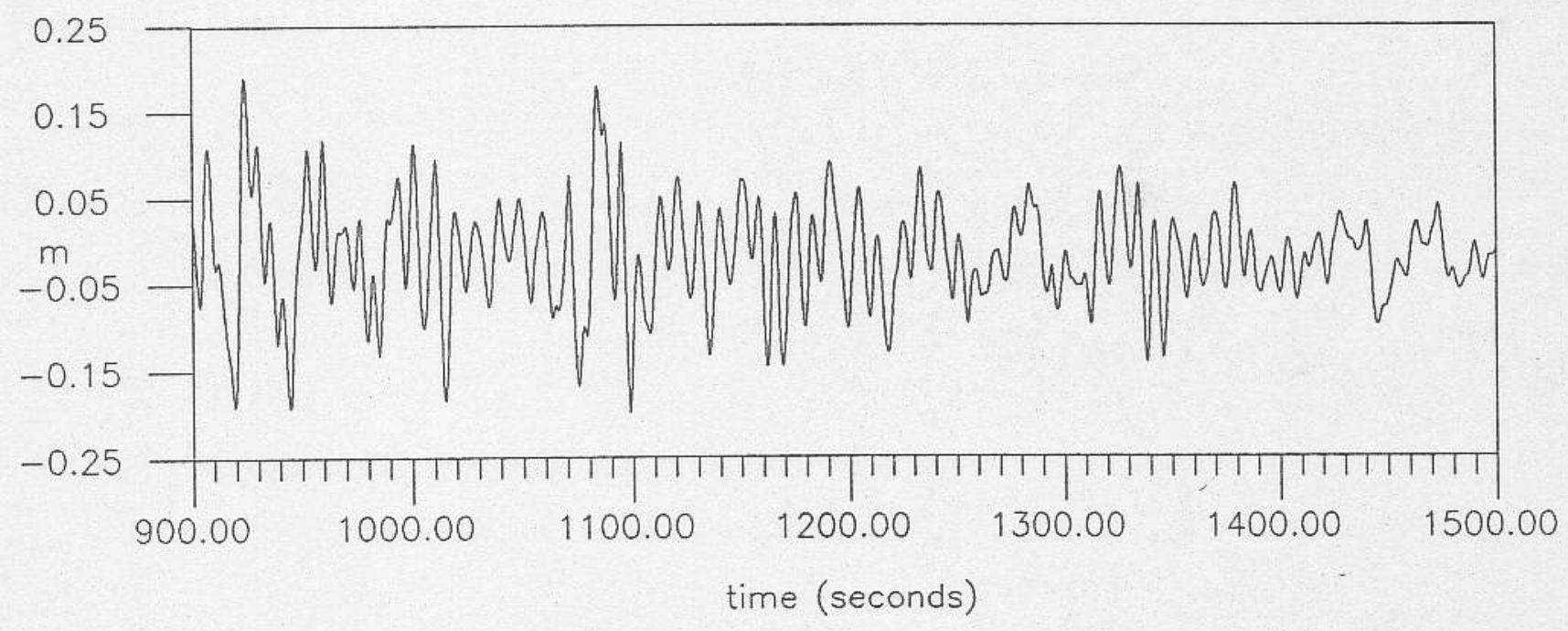

b) vertical displacement from integration of accelerometer signal

Fig. 12 Comparison of data from vision system and processed accelerometer signals 


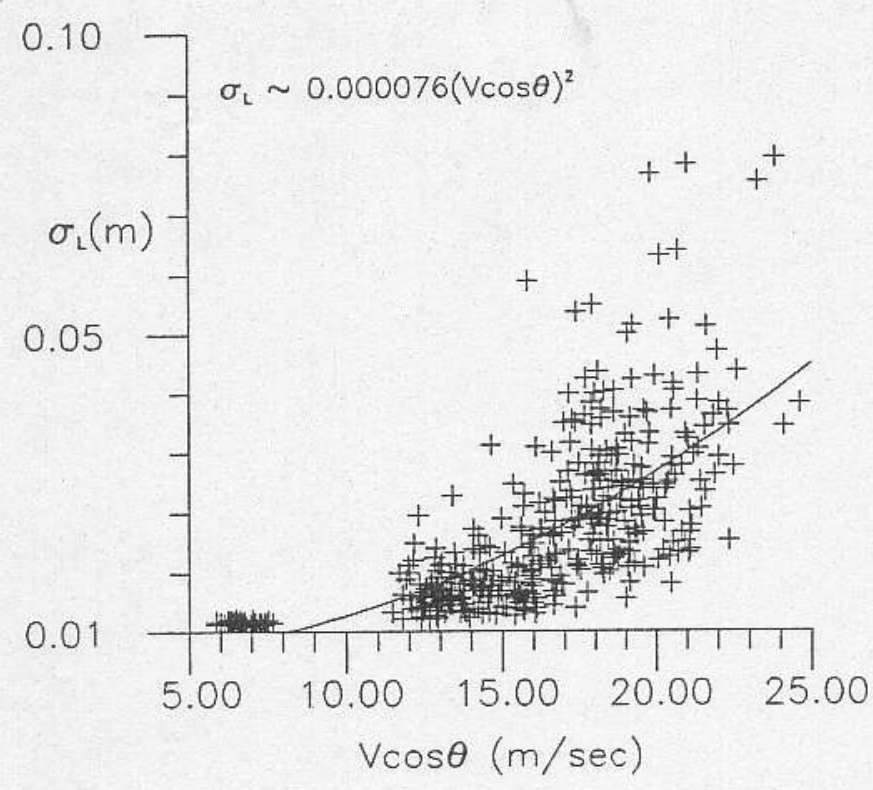

a) horizontal displacement, $\sigma_{L}$

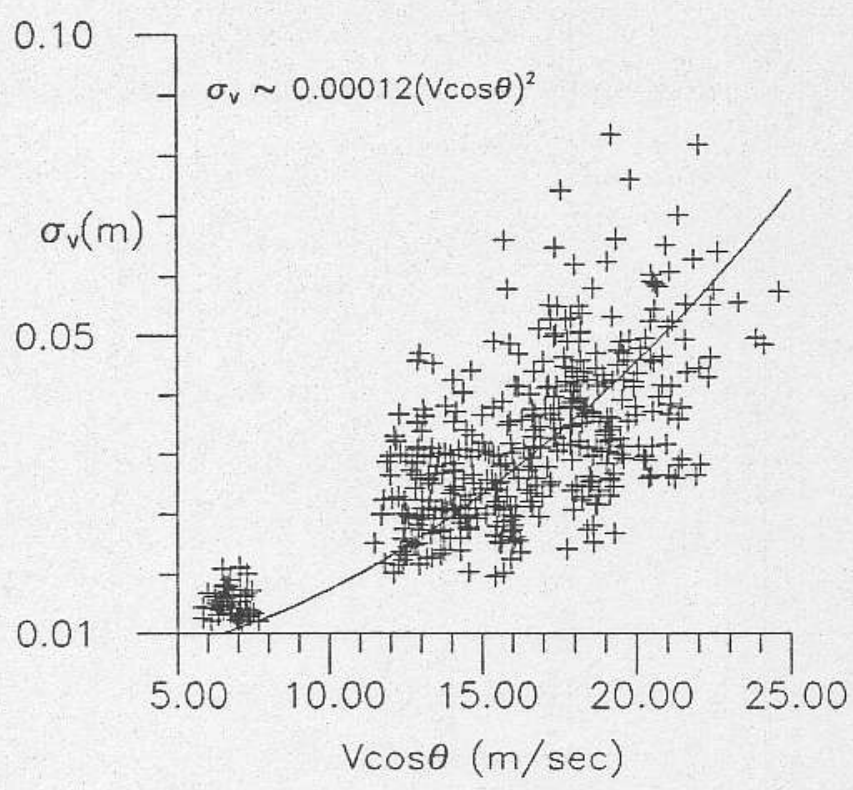

b) vertical displacement, $\sigma_{v}$

Fig. 15 Correlation of 64-second standard deviation values of displacement with wind speed 